\title{
De súplica a pseudo-debate: Helena 894 ss.*
}

\author{
From supplication to pseudo-debate: Helen 894 ff. \\ Carmen Morenilla \\ Universitat de València, España \\ carmen.morenilla@uv.es \\ (D) https://orcid.org/0000-0002-2570-1095 \\ Núria Llagüerri \\ Universitat de València, España \\ nuria.llaguerr@uv.es \\ (iD https://orcid.org/0000-0002-0710-5062
}

\section{Resumen:}

En Helena la pareja Helena y Menelao deben suplicar a Teónoe que no informe a su hermano Teoclímeno de la presencia de Menelao en Egipto, pero Menelao se niega a hacerlo y adopta una actitud diferente. Este rito de súplica truncado se transforma en un supuesto debate, que tampoco lo es.

Palabras clave: Eurípides, Helena, Súplica.

\section{Abstract:}

In Helen, the couple Helen and Menelaus pleads with Theonoe not to inform his brother Theoclymenus of the presence of Menelaus in Egypt, but Menelaus refuses to do so and adopts a different attitude. This truncated rite of supplication turns into a supposed debate, which it is not either.

KeYWORDS: Euripides, Helen, Supplication.

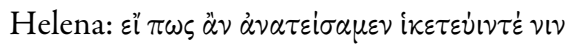

Si de algún modo ambos la convenciéramos suplicándole (v. 825) ${ }^{1}$

Con estas palabras responde Helena a la pregunta de Menelao sobre las posibilidades de poder salir vivos de Egipto: si ambos suplican a Teónoe que guarde silencio y no avise a su hermano, el rey Teoclímeno, podrán salvarse; en caso contrario no, porque ella, en tanto que adivina, ya sabe que Menelao está en Egipto. Menelao, en cambio, opina que es solo Helena la que debe hacerlo, aduciendo la conocida solidaridad femenina como motivo para no adoptar él esa actitud. Helena, por lo tanto, inicia el rito de súplica que queda truncado por la decisión de Menelao y lo sustituye, como veremos, por una rhêsis a medio camino entre la rhêsis de persuasión y una sarta de amenazas.

Helena es una obra contradictoria en muchos aspectos. Incluso su final, que parece el típico final feliz de la comedia de Menandro, en realidad deja un fuerte regusto amargo: miles de griegos y de troyanos han muerto y un reino ha sido destruido por una túnica vacía. La amargura que rezuma la rhêsis inicial de Helena, que se sabe utilizada por el que dicen, según ella, que es su padre, que ha urdido un plan para descargar de peso a una sobrecargada Tierra, es constante a lo largo de toda la obra, incluyendo el momento de la anagnórisis, que debía ser gozosa. 
El esperado regreso triunfal de los héroes que tomaron Troya es sustituido por la llegada de un amargado Teucro, primero, ${ }^{2}$ y, después, por la entrada en escena de un maltrecho náufrago, Menelao, vestido con harapos de lo que quedaba de las velas de su barco, el cual ha perdido a casi todos sus hombres, unos en Troya, otros en el mar, y al que cierra el paso al interior de palacio una anciana portera. No pudo haber una escena más dolorosa de contemplar para los familiares de aquellos que perecieron en el mar en la expedición a Sicilia, que tan exitosa se presumía cuando se planeó y que bien pronto se vio que iba a ser un desastre. ${ }^{3}$ La tremenda mortandad de hombres en ese terrible suceso de la vida real ateniense no puede más que ser recordada constantemente en esta tragedia en esos héroes caídos en desgracia que hablan de miles de muertos y de regresos a casa truncados. ${ }^{4}$

Es una tragedia contradictoria porque, aunque se trata de una obra en la que el factor humano es el definitivo, es decir, el ser humano es el que toma las decisiones sobre las actuaciones futuras, la presencia de la divinidad es constante desde el comienzo hasta el final: se inicia con una rhêsis en la que Helena habla de las intervenciones de Zeus, Hera y Hermes en el asunto de Troya y acaba con la intervención de los Dioscuros, que, además de traer información y órdenes, nos recuerdan que Helena es una semidiosa. ${ }^{5}$ El escenario inicial es una tumba, la del anterior rey, el sabio y pío Proteo, en el que se halla acogida Helena como suplicante en lugar sacro para impedir ser violentada por el rey Protesilao, y al final de la obra escapan los esposos fingiendo realizar un rito funerario por un supuestamente fallecido Menelao. Y en la parte central, en el lugar que debía ocupar el agón, se encuentra la escena de Teónoe, la sacerdotisa adivina hermana del rey ${ }^{6}$ que sale a informar de la decisión de una asamblea de dioses sobre el futuro de Helena, pasaje del que nos ocuparemos aquí.

Por todo ello no podía faltar en esta tragedia un elemento tan relevante del sentimiento religioso griego como los ritos, a algunos de los cuales ya nos hemos referido. En la escena de confrontación con Teónoe vamos a ver cómo Eurípides imbrica los factores divino y humano formando una compleja estructura. Sobre el especial carácter de la sacerdotisa y augur llama la atención Pohlenz (1930, p. 416), porque, en su opinión, con él quiere Eurípides mostrar la importancia de la sensatez, del sentido común, también en las cuestiones religiosas; pero, además, en sus manos, en manos de una mortal, está la salvación de Menelao y Helena, pues ella ha de decidir si les ayuda o si secunda al hermano. Esta es la razón por la que este estudioso afirma que en esta obra se produce la "profanación interna" de la tragedia. ${ }^{7}$

Die Entscheidungen über das, was wesentlich das Schicksal des Menschen bestimmt, fallen nicht in einem Rate launenhafter Götter, sondern in seiner eigenen Brust. Da liegen für ihn die Gefahren, aber auch seine höchsten Lebenswerte. Das ist die tiefernste Überzeugung, die Euripides hier ausspricht. Und das ist es, was dieses scheinbar scherzhafte Drama zur Tragödie macht. Tragisch ist auch hier das Menschenleben mit seinen Irrungen und Wirrungen; zugleich wird aber sichtbar, was den Menschen über Aussenwelt und Tyche erhebt. (...) Die Helena ist kein Kampfstück. Aber in ihr kommt zu klarem Ausdruck, worauf die Entwicklung der euripideischen Kunst seit langem hindrängte: die Auflösung von dem religiösen Hintergrunde, die innere Profanierung der Tragödie.

Ciertamente es ésta una figura muy interesante, en cuyas palabras aparecen las reflexiones de mayor calado sobre la justicia, sobre la responsabilidad de la persona con respecto a los demás y sobre la existencia de unos principios divinos. $^{8}$

La escena que nos interesa está estructurada en cuatro parlamentos, el primero y el último en boca de Teónoe, que enmarcan el de Helena y el de Menelao. Se trata del falso agón, a partir del v. 865, la escena en la que Helena primero, Menelao después exponen a Teónoe las razones por las que no debe informar a su hermano de la llegada de Menelao, a lo que sigue la rhêsis en la que Teónoe comunica su decisión. No es un agón en sentido estricto, puesto que no hay disparidad de opiniones, sino dos visiones de una misma posición, con las que se busca persuadir al personaje que debe decidir, y la respuesta de la sacerdotisa aceptando la propuesta. ${ }^{9}$ La simetría y la estructura de los dos discursos de la sacerdotisa entre sí y los de los esposos han sido puestas de manifiesto. ${ }^{10}$ Esas diferencias están remarcadas por la presentación y la gestualidad de los personajes. 
Eurípides reviste de solemnidad la salida a escena de Teónoe, lo que no ha pasado desapercibido a los críticos, algunos de los cuales se han esforzado en buscar relaciones con diferentes creencias y ritos. ${ }^{11}$ Probablemente la disparidad de opiniones esté causada porque el texto no permite la atribución a ningún culto concreto, lo que debe ser buscado por el autor, que no quiere adscribirla claramente a ninguno. A Helena se dirige Teónoe tras los ritos de purificación y por ello Helena es la primera en hablar: es ella quien conoce a la sacerdotisa, que le ha manifestado ya en otras ocasiones su simpatía. Lo hace recordando la escena anterior en la que una angustiada Helena, acompañada del coro, ha entrado en palacio para preguntar a la adivina por su esposo, dado que Teucro le ha informado de que lo dan por muerto. Sale Teónoe recordándole las palabras de ánimo que le pronunciara anteriormente, en las que le avisaba de la cercanía del esposo.

También en los movimientos de Helena y Menelao podemos ver el deseo del autor de caracterizarlos de modo diferente. La primera en responder es Helena, a la que se ha dirigido Teónoe e inicia su parlamento como suplicante, siguiendo lo que había hablado con Menealo y, en particular, lo que le había sugerido en elv. 825:

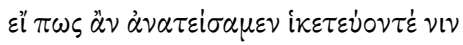

Si de algún modo ambos la convenciéramos suplicándole.

Helena se refiere a ellos dos, a los esposos, pues están ambos implicados por igual, razón por la que utiliza

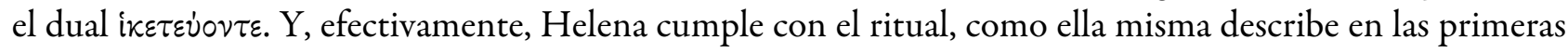
palabras que dirige a Teónoe, vv. 894-96:

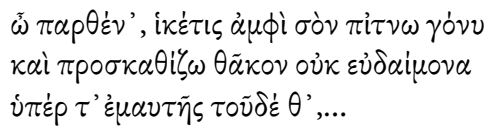

¡Oh, doncella! Como suplicante en torno a tus rodillas me postro y permanezco aquí sentada no como una persona dichosa en favor de mí misma y de este,...

A ello sigue el habitual discurso de persuasión, que, como hemos comentado, está muy bien construido desde la perspectiva retórica.

Pero, a pesar de la sugerencia que hace Helena, que es quien planea la salida a los problemas ante un Menelao desamparado, que, salvo echar mano de la espada, no sabe cómo actuar, él la desatiende y abiertamente declara no asumir el papel de suplicante, vv. 947 ss.:

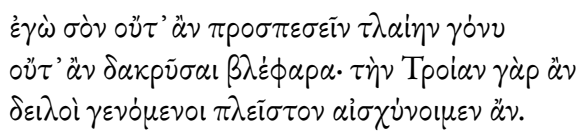

Yo ni osaré caer a tus rodillas ni que mis ojos viertan lágrimas; pues a Troya, transformados en cobardes, más avergonzaríamos.

El rito de súplica que Helena proponía queda, pues, truncado y es sustituido por un discurso a medio camino entre la persuasión y la amenaza, con la misma estructura que el de Helena, pero en un tono totalmente distinto.

Afirma Menelao que no puede asumir el papel de suplicante porque sería indigno de un héroe de Troya como él y argumenta que, aunque en los momentos terribles también los nobles lloran, él considera que con ello renunciaría a su virilidad:

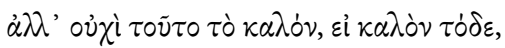

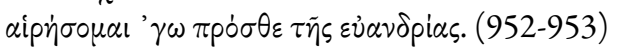

Pero esta actitud noble, si es noble esto, no lo escogeré yo por delante de la virilidad. 
No se mostró, sin embargo, tan aguerrido en el diálogo con la anciana portera, ante la que incluso invocó el derecho de inviolabilidad en tanto que náufrago y que extranjero:

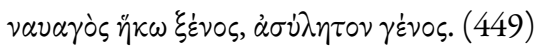

Náufrago extranjero he llegado, por naturaleza de asilo inviolable.

Derecho que en verdad asiste a los náufragos extranjeros entre los griegos, pero que no afecta a Teoclímeno, sea porque es egipcio y las normas de convivencia y religiosas son otras, sea por su carácter impío: recordemos que la anciana informa a Menelao de que Teoclímeno mata a todos los griegos que llegan a sus costas por temor a que puedan dar información de la mujer a la que retiene y con la que quiere casarse, aunque sea a la fuerza, Helena.

La desesperación de Menelao ante la falta de ayuda en esta escena inicial es tal que la anciana en el v. 456 señala que Menelao está llorando:

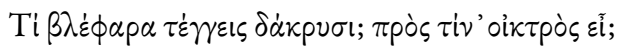

¿Por qué se te bañan los ojos de lágrimas? ¿A quién quieres provocar lástima?

Frente a esta actitud, que a muchos ha parecido cómica, pero que, en nuestra opinión, depende del modo de ser ejecutada por los actores, ahora, ante Teónoe, Menelao se envalentona y habla de matanzas y suicidios vertiendo sangre sobre la tumba de Proteo para forzar la decisión de la hija.

Helena habla de la justicia y el respeto filial, así como de su situación de madre y esposa que no puede ejercer de tal. Acorde con ello se observan interpelaciones de tipo emotivo y referencias a la posición que adopta

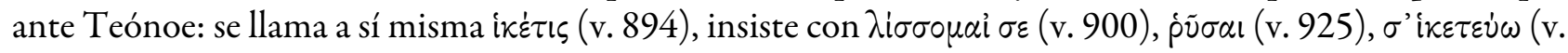
939). Menelao, en cambio, explícitamente rechaza esa actitud (vv. 947 ss.) y acorde con ello le pide a Teónoe que actúe según lo que considere justo, aunque también apela a sus sentimientos, pero no a la solidaridad femenina, sino en este caso a los filiales: se dirige a la tumba de Proteo y a él le habla; y a través de él también a Hades. $^{12}$

Menelao utiliza en lo fundamental los mismos argumentos que Helena con la importante diferencia de que donde ella habla de su situación como madre y esposa, del dolor que le provoca a ella y a sus familiares más cercanos lo que su eídolon ha causado y de las esperanzas de poder volver a su hogar, Menelao habla de las consecuencias que tendría la negativa de Teónoe, es decir, que mataría a Helena y se suicidaría sobre la tumba de Proteo. ${ }^{13}$

En la respuesta de Teónoe, vv. 998-1029, no hay referencia a los motivos de tipo afectivo, ni al perteneciente al ámbito doméstico femenino ni al cruento del héroe. Teónoe, en el mismo tono con el que habló en el primer parlamento, centra su intervención segunda en el respeto a los dioses y en reflexiones sobre la justicia y el buen nombre. La insistencia en el deseo de hacer lo justo, además de no traicionar la memoria del padre, está enmarcada en unas manifestaciones de tipo claramente religioso, en las que se mezcla el reconocimiento del respeto debido a los dioses tradicionales con reflexiones que apuntan a un sentimiento religioso personal.

En lo que hace a lo primero, es muy significativo que Teónoe vuelva a recordar la actitud contrapuesta de las dos diosas, Hera y Afrodita, se esfuerce en no agraviar a Afrodita y acabe aconsejando a los esposos que también ellos se encomienden a las diosas. Pero entre una y otra mención a las diosas manifiesta Teónoe creencias en el mundo de ultratumba que no son las tradicionales.

Es muy llamativa la composición anular, en la que se insiste en el respeto y el buen nombre, por ejemplo,

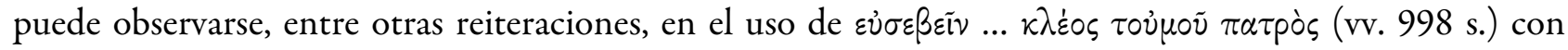

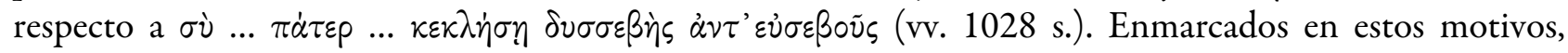
pronuncia Teónoe los cuatro versos centrales, vv. 1013-1016, que desarrollan un pensamiento estrechamente 
relacionado con las reflexiones sobre la importancia de tener un comportamiento correcto y sobre el respeto al padre fallecido, pero que adoptan una forma nueva:

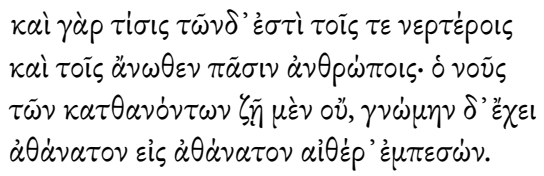

Pues también una compensación por estos hechos existe, para los de abajo y para los de arriba, para todos los humanos; la mente de los que han muerto no vive, pero tiene un conocimiento inmortal tras haberse unido al inmortal éter.

Teónoe termina de justificar la decisión de ayudar a Helena y Menelao formulando la idea de que existe una compensación o castigo tanto para los vivos como para los muertos, porque la gnóme es inmortal, ya que mantiene la consciencia tras la muerte. La originalidad de este planteamiento es la causa de que estos cuatro versos fueran atetizados por Nauck, Dindorf, Hartung, Kirchhoff, entre otros. ${ }^{14}$

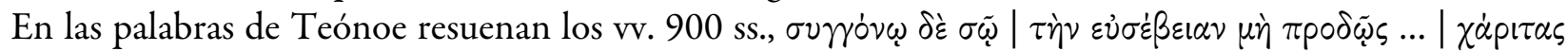

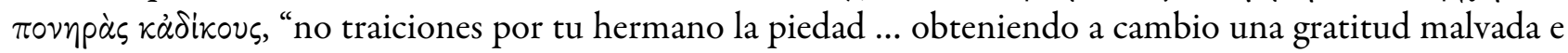
injusta”, que vuelven a reiterarse en los vv. 920 s., antes de la parte final, en la que se refiere Helena a su triste

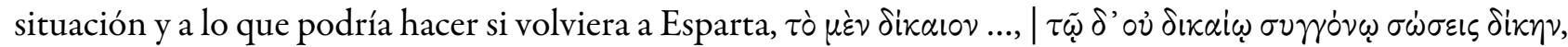

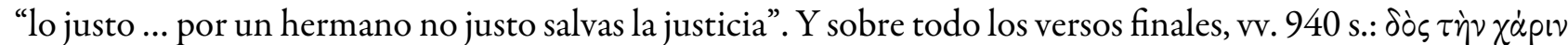

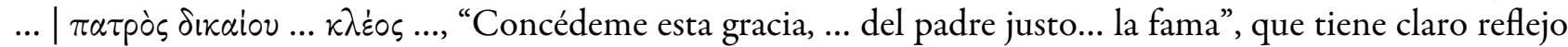

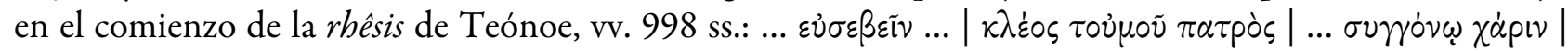

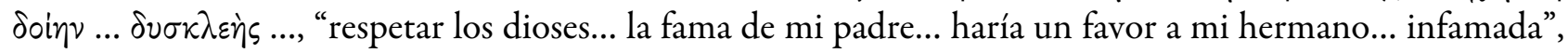

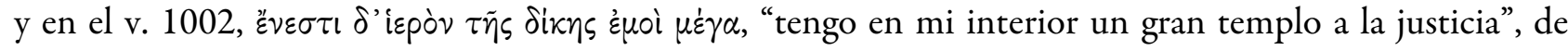
carácter sentencioso y con precedentes en otros autores que también reflexionan sobre la justicia. Dos veces en pocos versos (vv. 1017 y 1023) dice Teónoe $\sigma \iota \gamma \eta \dot{\sigma o \mu \alpha \iota, ~ " g u a r d a r e ́ ~ s i l e n c i o ": ~ c o n ~ e l l o ~ r e s p o n d e ~ a ~ l a ~ p e t i c i o ́ n ~}$ formulada por Helena en los primeros versos de su intervención, donde explícitamente le pide que calle, $\mu \dot{n}$

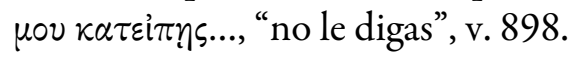

Como comentábamos, esta tragedia es una obra llena de contradicciones. A la ya bien estudiada contraposición apariencia vs. realidad, soma vs. psique, se añade el delicado equilibrio entre presencia de la divinidad y decisión humana, el uso de prodigios vinculados con la divinidad, como la desaparición en el aire de la Helena-nube, la realización de una asamblea de dioses en la que no se llega a una decisión consensuada, que se deja en manos de Teónoe, un falso rito funerario que sirve para salvar a los esposos, etc. En este marco la escena con la sacerdotisa cobra un papel especial. No es un agón, sino dos discursos de persuasión con estructura similar, pero tono diferente, exitosos, pues consiguen que la rhêsis de la contraparte manifieste la conformidad con las peticiones, a pesar de la actitud en absoluto de suplicante de Menelao.

La constante manifestación de dudas sobre versiones míticas por parte de los personajes, la reiterada elección de versiones menos conocidas o de innovaciones, no sólo en la historia principal, también en los detalles, ${ }^{15}$ que tanto ha llamado la atención de los investigadores, es un mecanismo más en el conjunto de convenciones dramáticas manipuladas hasta el límite por el autor, lo que es un rasgo esencial en esta obra: en toda ella, desde la concepción general del argumento, la estructura y el uso de motivos, la composición de las partes líricas corales y monódicas, el escenario, hasta en detalles de los relatos genealógicos o geográficos, Eurípides está recreando, transformando textos, mitos, relatos que ya conocemos, creados o utilizados antes por él o por otros autores y que forman parte del acervo cultural del público ateniense.

Eurípides se sirve de los más variados recursos incluyendo la exposición de variantes del mito no canónicas, para mostrar cómo va surgiendo la incertidumbre y la consciencia de la propia incapacidad del ser humano para llevar a término una acción eficaz y efectiva, sobre todo en las tragedias compuestas en los años que siguieron a la Paz de Nicias (421 a. C.). Se trata de obras, en las que se muestra una línea general de defensa de la paz y de sincera preocupación ante las nuevas aventuras bélicas. 
Con frecuencia se ha dicho que es esta una tragedia sin conflicto, con elementos cómicos, una tragicomedia. Sin embargo, la desazón que esta obra provoca no es propia de una comedia; y los elementos cómicos dependen en gran medida de la mirada del intérprete. ${ }^{16}$ Como muy bien dice Murray (1978, p. 116), "no es fácil precisar dónde está el punto flaco de la Helena. Tal vez nuestra impresión se deba a que los modernos no acabamos de entender el espíritu con el que se escribió la obra”.

Se ha considerado también que es una obra en la que los dioses pierden su prestigio y ceden el paso a los seres humanos. Y es cierto que se cuestiona la actitud errática de los dioses y a sus intermediarios, los adivinos, que no fueron sabedores del engaño de la nube, y se finge un rito como medio de poder lograr la salvación, lo que podría ser considerado impío. Pero también es cierto que en ella encontramos no solo una constante presencia divina sino incluso una manifestación de unas creencias religiosas íntimas, personales, que afectan a los principios básicos del comportamiento humano. ${ }^{17}$

Por ello, ese rito de súplica truncado por Menelao no debe pasar desapercibido, como tampoco el hecho de que Teónoe no haga referencia a sus amenazas y dirija su respuesta a Helena. Es constante la referencia a acciones cruentas en boca de Menelao, acciones que por una u otra razón no lleva a cabo, porque se lo impiden personajes femeninos que le hacen ver el despropósito de esas pretensiones violentas. El tiempo de las bravatas ha pasado, es el momento de la reflexión pausada, como también lo era en la terrible situación en la que se encontraban los atenienses en el año 412 a. C. Como señala Bañuls (2016, p. 80), "los atenienses se convirtieron en personajes de una tragedia colectiva, en unos héroes trágicos que arrastraron en su caída a todos los griegos, vencedores y vencidos".

\section{EDICIONES}

Grégoire, H. (Ed.). (1950). Euripide V. Hélène. Les Phéniciennes. París: Les Belles Lettres.

Dale, M. (Ed.). (1967). Euripides. Helen. Oxford: Clarendon Press.

Kannicht, R. (Ed.). (1969). Euripides. Helena, I-II. Heidelberg: Carl Winter Universitätsverlag.

Fusillo, M. (Ed.). (1997). Euripide. Elena. Milán: BUR.

Calderón, E. (Ed.). (2007). Eurípides, Heraclidas, Helena. Madrid: Alma Mater.

\section{REFERENCIAS}

Aélion, R. (1983). La technique dramatique d'Euripide et sa conception de la destinée humaine. En Jouan, F. (Ed.), Visages du destin dans les mythologies. Mélanges Jacqueline Duchemin (pp. 69-85). Paris: Les Belles Lettres.

Alves Torrano, J. A. (2010). O jogo de aparências e de opiniônes na tragédia Helena de Eurípides. Epos. Revista de Filología. Facultad de Filología de la UNED, 26, 13-32.

Assaël, J. (2001). Euripide, philosophe et poète tragique. Lovaina: Éditions Peeters.

Bañuls, J. V. (2016). Cuando la tragedia se hace historia y la historia tragedia. Nova Tellus, 34(2), 53-87.

Burian, P. (2007). Euripides. Helen. Oxford: Oxbow Books.

Calderón, E. (2006). Adivinos y arte adivinatoria en Eurípides. Prometheus, 32(2), 121-147.

Cerri, G. (1987). Le message dionysiaque dans l'Hélène d'Euripide. CGITA, 3, 197-216.

Collard, C. (2003). Formal Debates in Euripides' Drama. En Moosman, J. (Ed.), Euripides (pp. 64-80). Oxford: Oxford UP.

Conacher, D.J. (2003). Rhetoric and Relevance. En Moosman, J. (Ed.), Euripides (pp. 88-101). Oxford: Oxford UP.

Delcourt, M. (1939). Le suicide par vengance dans la Grèce ancienne. Revue de l'histoire des Religions, 1, 154-171.

de Oliveira Pulquério, M. (1975/76). A actuação dos deuses na Helena de Eurípides. Humanitas, 27/28, 209-225.

Di Benedetto, V. (1971). Euripide: teatro e società. Turín: Einaudi. 
Gallego, J. (2016). La asamblea, el teatro y el pensamiento de la decisión en la democracia ateniense. Nova Tellvs, 34(1), $13-54$.

Gilbert, P. (1949). Souvenirs de l'Égypte dans l'Hélène d'Euripide, AC, 18, 79-84.

López Cruces, J. L. (2007). Eurípides músico. Antíope y la reescritura de los mitos musicales. En Campos Daroca, J. et alii (Eds.), Las personas de Eurípides (pp. 3-37). Amsterdam: A.M. Hakkert.

Matthiessen, K. (1968/69). Zur Theonoeszene der euripideischen Helena. Hermes, 96, 685-704.

Morenilla, C. (2007a). La Helena de Eurípides. En Bañuls J.V. et alii (Eds.), O mito de Helena de Tróia à actualidade, vol. 1, (pp. 179-203). Coimbra: Universidade de Coimbra.

Morenilla, C. (2007b). La lealtad en un mundo convulso: Heléna y Andrómeda de Eurípides. En Bañuls, J. V.; Martino F. De y Morenilla, C. (Eds.), El teatro greco-latino y su recepción en la tradición occidental 2 (pp. 213-254). Bari: Levante Editori.

Murray, G. (1978). Eurípides y su tiempo. México: Fondo de Cultura Económica [trad. de la $1^{\mathrm{a}} \mathrm{ed}$ de 1913].

Pippin, A. (1960). Euripides' Helen: a comedy of ideas?. Cph, 55, 151-163.

Plácido, D. (1993). La expedición a Sicilia (Tucídides, VI-VII): métodos literarios y percepción del cambio social. Polis, 5, 187-204.

Pohlenz, M. (1930). Die griechische Tragödie. Leipzig-Berlín: B.G. Teubner.

Quijada, M. (1991). La composición de la tragedia tardia de Eurípides. Ifigenia entre los tauros, Helena y Orestes. Vitoria: Universidad del País Vasco.

Silva, M. F. (2005). Ensaios sobre Eurípides. Lisboa: Edições Cotovia.

Villacèque, N. (2013). Spectateurs deparoles! Délibération démocratique et théâtre à Athènes à l'époque classique. Rennes: Presses Universitaires de Rennes.

Wilamowitz-Moellendorff, U.v. (1963). Analecta euripidea. Hildesheim: G. Olms [reimp. Berlín 1875].

Zuntz, G. (1960). On Euripides'Helena. Theology and Irony. En AA.VV., Euripide. Sept exposés et discussions (pp. 199-241). Vandoeuvres-Ginebra: Fontation Hardt.

\section{Notas}

* Es obligado que manifestemos nuestra profunda deuda con José Vicente Bañuls Oller $(\dagger)$, compañero y maestro, de cuyas enseñanzas y de cuyos trabajos hemos obtenido conocimientos muy valiosos para la realización de este trabajo.

1 Mantenemos la lectura de los manuscritos, $\varepsilon \grave{\imath} \pi \omega \varsigma$, frente a $ٌ \sigma \omega \varsigma$, modificación de Krichhoff que aceptan habitualmente los editores.

2 Su padre, Telamón, lo ha mandado al exilio por no haber salvado a su hermano de padre, Ayante. Por ello acude Teucro buscando información sobre dónde poder fundar una ciudad y rehacer su vida.

3 Las relaciones entre la asamblea ateniense y el teatro han sido puestas de manifiesto por numerosos autores, entre ellos Villacèque, 2013, y recientemente Gallego, 2016, pp. 13-54.

4 Los bandazos que la asamblea ateniense daba durante los años de la Guerra del Peloponeso son muestra de esa inseguridad general y de la deriva peligrosa que muy pronto comenzó a seguir y que llevó a la polis ateniense al desastre. Los demócratas moderados, a cuyo mando estaba Nicias, pronto empezaron a perder posiciones ante los radicales, que se inclinaron por Alcibíades, quien, a pesar de que sus propuestas no siempre eran bien acogidas, consiguió convencerlos de realizar la mayor y más desastrosa expedición de la historia de Atenas. Es significativo que Tucídides en VII, 87, 5-6 concluya el relato de la expedición a Sicilia con unas palabras que evocan las que empleara Heródoto para referirse a la toma y destrucción de Troya (II, 120): sin duda, la magnitud del desastre le llevó a pensar en este pasaje, en el que todo un pueblo, el troyano, es aniquilado por una expedición panhelénica que sufrirá también las consecuencias de la forma desmesurada e impía en la que ha llevado a cabo la expedición. Cf. Bañuls, 2016, p. 82, donde señala los términos utilizados para designar el desastre total, en especial $\pi \alpha \nu \omega \lambda \varepsilon \theta p i \alpha$, hápax en Tucídides.

5 La intervención final de los Dioscuros tiene por objeto traer la concordia, un proceso similar al estudiado por López Cruces, 2007, pp. 31 ss.

6 La peculiaridad de este personaje, el fuerte contenido filosófico de sus palabras y el papel determinante en la acción han provocado que hayan sido muchos los estudios sobre ella; destacamos sólo a modo de ejemplo Matthiessen, 1968/69, pp. 
685-704 y Assaël, 2001, pp. 55 ss. estudia con detenimiento el avance en la concepción de una inmortalidad individual que puede deducirse en Eurípides a partir de este personaje.

7 Para una opinión en contra, que atribuye la responsabilidad de todo a Zeus, cf. de Oliveira Pulquério, 1975/76, pp. 209-225.

8 Teónoe termina de justificar la decisión de ayudar a Helena y Menelao contra los deseos de su hermano formulando la idea de que la $\gamma \nu \omega ́ \omega \eta$ es inmortal, por lo que mantiene la consciencia tras la muerte del cuerpo (vv. 998 ss.). Cabe recordar que según Heródoto (II, 123) los egipcios fueron los primeros en creer en la inmortalidad del alma, lo que en estos versos es presentado de un modo acorde al pensamiento de Eurípides. Quizá, cuando Platón en Crátilo $407 \mathrm{~b}$ dice que Atenea también es llamada Teónoe, esté recordando las creencias de la sacerdotisa egipcia.

9 Fusillo, 1997, p. 21, habla de "due complessi discorsi” y de un "agone senza conflitto", y Quijada, 1991, p. 158, de "escena de persuasión".

10 Así lo hacen Collard, 2003, p. 77, y Conacher, 2003, pp. 95 s., y especialmente Quijada, 1991, pp. 157 ss. y 163 ss.

11 Se ha apuntado posibles relaciones de los ritos de purificación de la salida a escena con el orfismo, con cultos propios de las sacerdotisas de Amón o con la prórresis de la procesión de Eleusis. Cf. Grégoire, 1950, p. 253; Gilbert, 1949 , pp. 79-84; más recientemente Cerri ha vuelto a retomar la idea de la existencia de una relación con rituales dedicados a Deméter, 1987, 197-216; por el contrario Calderón, 2006, cree que no puede adscribirse a un culto concreto.

12 Para la cuidada diferencia en la gestualidad de ambos cf. Silva, 2005, pp. $257 \mathrm{~s}$.

13 Sobre lo que significa esta terrible amenaza cf. Delcourt, 1939, pp. 154-171.

14 En contra de la atétesis se manifiesta Wilamowitz-Moellendorff, 1963, p. 164, n. 4; recientemente Burian, 2007, p. 253, se hace eco de la opinión de Grégoire y señala que la originalidad está en la creencia en la inmortalidad de la gnóme. Cf. Zuntz, 1960, pp. 234-238, páginas que reproducen la discusión de la conferencia en la que se manifiestan los problemas que plantean estos versos y se muestran dudas sobre su procedencia y sobre su ubicación en la tragedia, lo que ha dado lugar a que Assaël considere a esta joven sacerdotisa exponente de la función intelectual, a través de la cual, en su opinión, Eurípides quiere mostrar su preocupación por la naturaleza del conocimiento y el acceso a él por parte del ser humano, 2001, pp. 113-129, capítulo "L'éclat de l'intelligence et de la raison".

15 Esta es la causa de que Wright hable de "metamitología", concepto que define como la sistemática presentación del carácter ficcional del mito.

16 Algunos estudiosos han visto en algunas escenas de esta obra unos rasgos de comicidad, como en la escena entre la anciana portera y Menelao o el encuentro entre el anciano marino, compañero de Menelao, y la verdadera Helena. Como caso extremo puede citarse el trabajo de Pippin, "Euripides'Helen: a comedy of ideas?", CPh 55, 1960, pp. 151-163, en el que la autora interpreta y traduce desde un punto de vista cómico escenas que en principio no tienen necesariamente este tono, pero que son descontextualizadas y pasadas por el tamiz de la interpretación personal.

17 Di Benedetto, 1971, p. 290, sostiene que puede observarse un cambio de postura del autor desde Hécuba y Troyanas en el sentido de pedir respeto por la religión tradicional. 